\title{
Libertad y orden en la Filosofía política kantiana. Acerca de los límites del uso público de la razón en El conflicto de las Facultades
}

\author{
Freedom and order in Kant's political philosophy. \\ On the limits on the public use of reason \\ in The conflict of the faculties
}

\author{
ILEANA BEADE \\ CONICET, Argentina
}

RESUMEN. En este trabajo proponemos examinar una doble exigencia formulada por Kant en El conflicto de las Facultades -a saber, la exigencia de libertad y la exigencia del orden-, a fin de señalar la premisa básica subyacente a dicha exigencia, esto es: la idea de que el orden público constituye la condición fundamental para la preservación del estado civil, entendido como el único estado en el que los hombres pueden ejercer plenamente su derecho innato a la libertad. Atendiendo a este objetivo, examinaremos el modo en que Kant caracteriza la contienda entre las Facultades, destacando el sentido eminentemente político del conflicto, y analizaremos la función específica que asigna a cada una de las Facultades, haciendo especial énfasis en la determinación de los límites establecidos para el libre ejercicio de la razón filosófica.

Palabras clave: libertad, orden, uso público y uso privado de la razón, Kant.

Bajo el título general El conflicto de las Facultades [Der Streit der Fakultäten (SF)], Kant publica en 1798 tres opúsculos breves, el primero de los cuales se halla específicamente referido a la contienda entre las $\mathrm{Fa}$ -
ABSTRACT. This paper addresses a double demand formulated by Kant in The conflict of the Faculties -to wit: the demand for freedom and the demand for order-with the aim of pointing out the basic premise implicit in such demand: the idea that the public order constitutes the fundamental condition for the preservation of the civil state, as the only state within which human beings can fully exercise their innate right to freedom. We will examine the way that Kant characterizes the contest between the Faculties, stressing its essentially political meaning, and will also consider the specific function that he assigns to each of them, paying special attention to the limits he sets on the free exercise of philosophical reason.

Key words: freedom, order, public use and private use of reason, Kant.

cultades de Filosofía y Teología ${ }^{1}$. En ese escrito retoma algunas cuestiones previamente discutidas en el texto de 1784, Contestación a la pregunta: ¿Qué es Ilustración? [Beantwortung der Frage: Was ist Aufklärung? 
(WA) $]^{2}$, cuestiones entre las cuales nos interesa considerar aquí aquellas específicamente vinculadas con la reivindicación kantiana de la libertad de pensamiento y la libertad de expresión, a las que Kant consideró no sólo como derechos humanos inalienables, sino asimismo como la condición básica y fundamental de todo progreso político-jurídico. En ambos textos se establecen, sin embargo, límites precisos para el ejercicio de estas libertades, de manera tal que las mismas no constituyan una amenaza para la subsistencia del estado de derecho. En tal sentido cabría afirmar que la distinción entre los usos público y privado de la razón formulada en el escrito de $1784^{3}$ reaparece, implícitamente, en el escrito sobre las Facultades, en relación con la función específica que Kant asigna allí a las diversas Facultades: efecto, mientras los miembros de las llamadas Facultades superiores (Teología, Derecho y Medicina) -y especialmente aquellos que, habiendo recibido en ellas su instrucción, desempeñan ciertas funciones civiles de carácter públicodeben responder ante el gobierno, hallándose así sujetos a los límites propios del uso privado de la razón, los miembros de la Facultad inferior -i.e. la Facultad de Filosofía-se hallan autorizados, por el contrario, a hacer un uso público de la razón, pues de otro modo no podrían desempeñar, según veremos, su función propia y esencial, a saber: el libre examen de todo tipo de doctrinas.

En este trabajo, proponemos analizar los principios doctrinales subyacentes a esta doble exigencia formulada en los escritos jurídico-políticos kantianos, a saber la exigencia de libertad y la exigencia de orden, tal como aparece formulada en la primera parte de $E l$ conflicto de las Facultades. Este análisis intentará identificar la premisa básica subyacente a dicha exigencia, a saber: la idea de que el orden constituye la condición básica y fundamental para la preservación del estado civil, entendido como el único estado en el que los hombre pueden poseer derechos en general $^{4} \mathrm{y}$, por tanto, como único estado en el que resulta factible el ejercicio de nuestro derecho innato a la libertad. Atendiendo a este objetivo, en el primer apartado haremos referencia a los motivos de la contienda entre las Facultades, señalando su carácter esencialmente político. En el segundo apartado, examinaremos la exigencia de que se conceda absoluta libertad a la Facultad de Filosofía, exigencia fundada, según veremos, en la concepción kantiana de la razón como facultad esencialmente crítica y autónoma. En el tercer apartado examinaremos los principales argumentos aducidos por Kant a fin de justificar la necesidad de una determinación clara y precisa de los límites dentro de los cuales han de ser ejercitadas la libertad de pensamiento y la libertad de expresión, argumentos referidos - como hemos adelantado-a la necesidad de garantizar la continuidad del orden jurídico. Este recorrido permitirá mostrar de qué manera Kant logra articular dos exigencias aparentemente contrapuestas e igualmente necesarias - la de la libertad y la del orden-, exigencias que delinean las coordinadas básicas dentro de las cuales se inscribe su tratamiento de diversos problemas políticojurídicos, tales como la cuestión del derecho de resistencia, los límites del derecho de ciudadanía o el problema de la soberanía.

\section{El conflicto entre las Facultades como contienda política}

Así como en el texto sobre la Ilustración Kant exige que el Estado garantice plena auto- 
nomía a la razón en su uso público, reconociendo, sin embargo, la necesidad de restricciones en lo relativo a su uso privado ${ }^{5}$, así también en La contienda entre las $\mathrm{Fa}$ cultades de Filosofía y Teología ${ }^{6}$ establece que ha de concederse plena autonomía a los miembros de la Facultad de Filosofía, señalando, no obstante, los límites precisos dentro de los cuales ha de ser desarrollada la tarea crítica que han de llevar a cabo. Desde la perspectiva kantiana, estos límites resultan indispensables a fin de que el gobierno pueda garantizar la subsistencia del orden público, dando así cumplimiento a lo que constituye quizás su finalidad básica y fundamental, a saber: la preservación del Estado de derecho ${ }^{7}$. La preocupación constante de Kant por establecer tales límites se advierte ya en las observaciones iniciales del texto, referidas a las diversas modalidades bajo las cuales puede ser desarrollada la investigación científica:

Desde luego, no anduvo falto de inspiración aquél a quien se le ocurrió por primera vez la idea de tratar fabrilmente todo el conjunto del saber (propiamente las cabezas consagradas al mismo), proponiendo poner en práctica dicho proyecto mediante la división del trabajo entre tantos profesores o docentes públicos como disciplinas hubiese, los cuales, en tanto depositarios de las distintas materias, vinieran a constituir una suerte de comunidad científica, llamada Universidad (o Escuela Superior) con cierta autonomía [...]; semejante comunidad científica quedaría habilitada por medio de sus Facultades (las pequeñas y diversas corporaciones entre las que se distribuyen los integrantes de la Universidad en función de las distintas ramas del saber) [...]. Al margen de este gremio de eru- ditos cabe hallar sabios que no pertenezcan a la Universidad, sino que simplemente cultiven una parcela del vasto conjunto del saber, ya lo hagan formando parte de ciertas corporaciones independientes (denominadas Academias o también Sociedades Cientificas) o bien vivan, por decirlo así, en el estado de naturaleza del saber, donde cada cual se ocupa de ampliarlo o difundirlo a título de aficionado sin seguir pauta o regla algunas. Todavía cabe distinguir a los propiamente doctos de esos otros letrados (con estudios) que, al verse revestidos con un cargo, actúan como instrumentos del gobierno y en provecho propio (no precisamente en aras de las ciencias). [...]. Éstos, en cuánto órganos del gobierno (eclesiásticos, magistrados y médicos) ven sometido a la ley su influjo sobre el público en general y constituyen una clase especial de letrados que, lejos de ser libre para hacer un uso público de sus conocimientos, se halla bajo la censura directa de sus Facultades respectivas, ya que se dirigen directamente al pueblo, compuesto de legos en sus disciplinas (más o menos como el clero se dirige a los laicos) y el gobierno debe mantener el orden a fin de que, si bien detenten parte del poder ejecutivo dentro de sus especialidades, no acaparen el poder legislativo, ni tampoco se sustraigan al poder judicial que compete a las Facultades (SF, Ak. VII, 18).

En esta descripción de la estructura de la institución universitaria se refleja claramente el principio de una división del trabajo en el ámbito del conocimiento: las diversas disciplinas son desarrolladas al interior de una comunidad científica a la que se denomina Universidad en sentido propio, de manera tal que cada una de ella goza de cierta autonomía (necesaria para el desarrollo de su finalidad 
específica), hallándose no obstante integradas como partes de un todo que las comprende y hace factible un intercambio entre aquéllas. Por fuera de la comunidad universitaria, algunos eruditos o sabios se integran en corporaciones independientes (i.e. las llamadas Academias o Sociedades científicas), mientras que otros permanecen, por el contrario, "en el estado de naturaleza del saber", metáfora que alude a la situación desventajosa de aquellos que desarrollan su investigación por fuera de toda adscripción institucional. En efecto, el estado de naturaleza suele ser caracterizado, en los textos jurídico-políticos kantianos, como un estado sin ley ${ }^{8}$, es decir, como una instancia pre-política en la que el ejercicio de los derechos naturales del hombre quedaría librado a condiciones puramente contingentes e inciertas, debido a la ausencia de leyes públicas capaces de garantizarlos (en un estado tal, no resulta factible el desarrollo de las disposiciones humanas originarias ni, por consiguiente, el progreso del género humano en su conjunto). De manera análoga, quienes permanecen en el estado de naturaleza del saber intentan ampliar el conocimiento privados de las ventajas que reporta la estructura propia de la institución universitaria, cuyo funcionamiento se halla regulado por una serie de estatutos cuyo propósito no es limitar la autonomía individual, sino por el contrario, garantizar las condiciones indispensables para su ejercicio. Esta metáfora política revela, pues, una concepción de la Universidad como un ámbito especialmente idóneo para el desarrollo de la investigación científica, ámbito que hace posible una suerte de Estado de derecho en el dominio del saber, en cuyo marco las capacidades individuales puedan ser plenamen- te desarrolladas a través de mecanismos institucionales coactivos, que constituyen el marco legal indispensable para tal desarrollo.

Más allá de esta distinción en clave política entre los letrados universitarios y aquellos que ejercen sus investigaciones por fuera de la Universidad y de otras instituciones científicas independientes, Kant considera el caso de los negociantes del saber, aquellos letrados que, habiendo cursado estudios universitarios, ejercen ciertas funciones públicas, desempeñándose así como órganos del gobierno. En lo que atañe a las doctrinas que imparten ante el pueblo, tales funcionarios deben responder ante sus respectivas Facultades y, por medio de éstas, ante el gobierno, pues éste -tal como advierte Kant en el pasaje previamente citado- debe mantener el orden, siendo ésta una de sus funciones básicas y elementales. Quienes en razón de su actividad profesional se desempeñan como ministros del gobierno han de atenerse, al menos en lo referido al ejercicio de su función pública, a las prescripciones de aquél y no se hallan autorizados, pues, a hablar en nombre propio, siendo la censura que las respectivas Facultades ejercen sobre tales funcionarios el medio del cual se sirve el gobierno a fin de ganar influencia sobre el pueblo, garantizando así el orden público.

Las metáforas económicas, jurídicas y políticas son recurrentes a lo largo del texto. Así se indica, por ejemplo, que en su carácter de funcionarios públicos, los eclesiásticos, magistrados y médicos retienen "parte del poder ejecutivo dentro de sus especialidades", esto es: conservan la capacidad de tomar ciertas decisiones al momento de interpretar los estatutos públicos vigentes, pero siempre bajo la condición de que su ejerci- 
cio profesional en tanto órganos del gobierno no resulte afectado. En tal sentido se observa que aquéllos no han de "acaparar el poder legislativo" (que es prerrogativa exclusiva del gobierno), sino que han de someterse de buen grado "al poder judicial que compete a las Facultades", lo cual significa, básicamente, que el gobierno se reserva el derecho de decidir qué tipo de doctrinas resultan más convenientes para ser públicamente impartidas (decisión que resultará vinculante para las Facultades superiores). Un breve recorrido de los aspectos temáticos desarrollados en este escrito de 1798 revela que estas y otras metáforas no han de ser interpretadas como mero instrumento retórico, pues las mismas expresan de manera elocuente -y casi literal- el carácter esencialmente político del problema en cuestión. La contienda [Streit] entre las Facultades es, en efecto, una diputa política, que involucra como actores principales al gobierno, a los sabios o letrados (ya se trate de los intelectuales en general, o bien de aquellos que se desempeñan como funcionarios públicos) y, finalmente, al pueblo, el cual, según veremos, deberá permanecer al margen de la disputa, lo cual no impide, sin embargo, que sea considerado como uno de sus actores principales, habida cuenta de que la contienda tiene lugar, precisamente, en torno a la influencia que las Facultades procuran ejercer sobre él: en efecto, mientras el gobierno intenta ganar influencia sobre el pueblo a través de las doctrinas impartidas por las Facultades superiores, la Facultad inferior se halla abocada al examen crítico de todo tipo de doctrinas (en aras de la verdad y el progreso de las ciencias ${ }^{10}$ ), situación que genera un conflicto inevitable entre ellas, el cual no ha de resultar, sin embargo, perjudicial para el or- den civil, siempre que sea encausado dentro de ciertos márgenes institucionales.

En lo que respecta a la función propia de la llamada Facultad inferior, quienes se hallan abocados a la investigación filosófica pueden exigir al gobierno plena autonomía para el desarrollo de sus investigaciones, pues es tarea propia de la filosofía examinar con total libertad todo tipo de doctrinas en beneficio del progreso de las ciencias y, en última instancia, del propio gobierno:

hay que conceder a la comunidad científica otra Facultad, que sea independiente de los mandatos del gobierno con respecto a sus doctrinas y tenga la libertad, no de dar orden alguna, pero sí de juzgar todo cuanto tenga que ver con los intereses científicos, es decir, con la verdad, terreno en el que la razón debe tener el derecho de expresarse públicamente [die Vernunft öffentlich zu sprechen berechtigt sein $т u \beta]$, ya que sin ello la verdad nunca llegaría a manifestarse (en perjuicio del propio gobierno), dado que la razón es libre conforme a su naturaleza y no admite la imposición de tomar algo por verdadero (no admitiendo credo alguno, sino tan sólo un credo libre). El hecho de que dicha Facultad sea tildada de «inferior», pese a contar con ese enorme privilegio (de la libertad), halla su causa en la naturaleza del hombre; pues quien puede mandar, aunque sea un humilde servidor de algún otro, se ufana de ser más importante que quien no manda sobre nadie, pero es libre (SF, Ak. VII, 19-21) ${ }^{11}$.

Así como en el escrito sobre la Ilustración se formula la exigencia de que la razón sea eximida de toda sujeción a autoridades externas en el ámbito de su uso público, así se reclama, en el escrito sobre la contienda de 
las Facultades, libertad plena para aquellos abocados a la reflexión filosófica. En tal sentido cabría afirmar que el universo de lectores al que se refiere Kant en 1784 a fin de circunscribir el ámbito idóneo para el ejercicio del libre pensamiento (esto es, un ámbito en el cual la libertad absoluta en el ejercicio crítico de la razón no constituya una amenaza para la subsistencia del orden civil) se halla restringido, en el escrito de 1798, a los intelectuales específicamente abocados a la investigación filosófica ${ }^{12}$. La distinción entre los usos público y privado de la razón -y la exigencia de una estricta limitación de este último, vinculada a la necesidad de garantizar el orden- reaparece, pues, en el texto sobre las Facultades, referida a una situación particular: en efecto, la Facultad de Filosofía es identificada allí como el ámbito institucional en el que ha de concederse absoluta libertad a la razón, a fin de que ésta pueda desempeñar su tarea propia y distintiva. Por el contrario, los miembros de las $\mathrm{Fa}$ cultades superiores, y en particular aquellos que se desempeñan como funcionarios públicos, se hallan comprometidos a hacer un uso privado de la razón ${ }^{13}$, al menos en lo que atañe al ejercicio de sus funciones civiles ${ }^{14}$. El punto decisivo es que esta suerte de $d i$ visión del trabajo intelectual genera una disputa que ha de ser regulada, de manera tal que no afecte a la estabilidad del orden vigente, sino que contribuya, por el contrario, a un perfeccionamiento gradual de las instituciones políticas y jurídicas. Para que esto sea posible, es necesario que los miembros de la Facultades superiores se atengan a los mandatos gubernamentales en todo aquello que concierne a las doctrinas públicamente impartidas (esto es, que accedan a los límites que resultan indispensables en el marco del llamado uso privado de la razón). Es igualmente necesario, por otra parte, que los miembros de la Facultad inferior puedan desarrollar su actividad crítica sin ser obstaculizados por las Facultades superiores ni por quienes ejercen el poder político ${ }^{15}$. En el apartado siguiente haremos mayor referencia a esta segunda exigencia, la cual se funda, según veremos, en la concepción kantiana de la razón como facultad esencialmente crítica y autónoma.

\section{El principio del laissez faire en} el ámbito del conocimiento y el libre uso público de la razón filosófica

Hemos señalado que tanto en el escrito sobre la Ilustración como en el texto sobre las Facultades, Kant formula la exigencia de que el gobierno conceda plena libertad a quienes se hallan abocados al ejercicio crítico de la razón, actividad que resulta indispensable no sólo para el progreso de las ciencias, sino asimismo para el perfeccionamiento de las instituciones político-jurídicas (y, en sentido amplio, para el progreso del género humano hacia un estado de mayor perfección) ${ }^{16}$. A través de una elocuente metáfora, Kant formula, en El conflicto de las facultades, la demanda básica que la razón filosófica eleva ante el poder político:

Cierto ministro francés convocó a algunos de los comerciantes más reputados, con objeto de recabar sus propuestas respecto de cómo restablecer el comercio, como si él fuera capaz de elegir las mejores entre ellas. Después de que varios hubieran emitido su parecer, un viejo comerciante, que había guardado silencio hasta entonces, dijo: «Haga buenos caminos, acuñe buena moneda, proporciónenos 
un derecho de cambio ágil y todo eso, pero respecto a lo demás, ¡déjenos hacer!». Una respuesta similar sería la que habría de dar la Facultad de Filosofía, cuando el gobierno le preguntase sobre la doctrina que ha prescrito al estudioso en general: «limitarse a no estorbar el progreso del conocimiento y de las ciencias (SF, Ak. VII, 19).

Ya en la Crítica de la razón pura (en la sección titulada "La disciplina de la razón pura con respecto a su uso polémico" ${ }^{\text {"17), }}$, Kant identifica la crítica como la tarea propia y esencial de la razón. Haciendo referencia a los recelos que suelen despertar las indagaciones filosóficas entre aquellos que ejercen el poder político, señala la necesidad de conceder absoluta libertad a la razón, que ha de ser ejercitada, en todo caso, atendiendo a reglas y principios inmanentes ${ }^{18}$. En relación con las especulaciones escépticas de Hume, invoca allí el principio del laizzes faire en el ámbito de la reflexión filosófica:

¿Qué se ha de hacer aquí, especialmente en atención al peligro que parece amenazar desde aquí al bien común? Nada es más natural, nada es más justo, que la decisión que debéis tomar sobre esto. Dejad hacer a esa gente; si ponen de manifiesto talento, si ponen de manifiesto una investigación profunda y nueva, en una palabra, con sólo que pongan de manifiesto razón, entonces siempre gana la razón. Si recurrís a otros medios que los de una razón libre de coacción; si clamáis alta traición; si convocáis al público, que no entiende de tan sutiles elaboraciones, como si tocárais a incendio, os ponéis en ridículo. Pues no se trata de lo que sea provechoso o perjudicial para el bien común, en estas cosas, sino solamente [se trata] de hasta dónde puede llegar la ra- zón en su especulación que hace abstracción de todo interés [...]. En esta dialéctica no hay victoria alguna que pueda daros motivos para inquietaros (A746-747/B 774-775).

Recurriendo a elocuentes metáforas políticas, Kant observa que quienes ejercen el poder no han de temer por los resultados a los que pudiese conducir el libre uso de la razón:

Sin ella [la crítica] la razón está como en estado de naturaleza, y sólo puede hacer valer, o proteger, sus afirmaciones y pretensiones mediante la guerra [durch Krieg]. La crítica, en cambio, que todas las decisiones las extrae de las reglas fundamentales de su propia institución, y cuya autoridad nadie puede poner en duda, nos trae la tranquilidad de un estado de Derecho, en el cual no tenemos que resolver nuestras disputas de otro modo que mediante un proceso. Lo que pone fin a las pendencias, en el primer estado, es una victoria, de la cual ambas partes se jactan, y a la cual la mayoría de las veces sigue sólo una paz insegura instituida por la autoridad, que se interpone; en el segundo [estado], [lo que pone fin a las pendencias] es la sentencia, que, al alcanzar, aquí a la fuente misma de las controversias, debe garantizar una paz perpetua (A 751-752/B 779-780).

El uso recurrente de metáforas políticas en el contexto de una reflexión acerca de la actividad propia de la razón no resulta casual. Kant parece ser plenamente consciente del potencial político ínsito en el ejercicio crítico de la razón ${ }^{19}$, y si se ocupa constantemente de señalar que la libertad de pensamiento no ha de ser temida como una amenaza para la subsistencia del orden civil, es precisamente porque advierte que la razón 
lleva en sí, en cierto modo, el germen de la subversión, por cuanto no reconoce autoridad ni legislación alguna por encima de la que ella se dicta a sí misma:

De esta libertad forma parte también la de exponer al juicio público, sin ser por eso acusado de ser un ciudadano revoltoso y peligroso, los propios pensamiento, [y] las propias dudas que uno no puede resolver por sí mismo. Esto reside ya en el derecho originario de la razón humana, la cual no reconoce otro juez que la misma razón humana universal, en la que cada uno tiene su voz; y como de ésta debe venir toda mejora de la que nuestro estado sea capaz, ese derecho es sagrado y no puede ser restringido (A 752/B 780).

La autonomía constituye, pues, la condición básica e indispensable para el ejercicio de la reflexión filosófica, o de la razón sin más, pues ésta no puede someterse a coacción externa sin comprometer con ello su función propia y distintiva. De allí que el gobierno deba restringir su influencia directa a las Facultades superiores, eximiendo, sin embargo, a la Facultad de Filosofía de toda prescripción:

Ahora bien, a la capacidad de juzgar con autonomía, esto es, libremente (conforme a los principios del pensar en general), se le llama razón. Y por lo tanto, la Facultad de Filosofía, en cuanto debe ser enteramente libre para compulsar la verdad de las doctrinas que debe admitir o simplemente albergar, tiene que ser concebida como sujeta tan sólo a la legislación de la razón y no a la del gobierno (SF, AK. VII, 27).

Kant señala en reiteradas oportunidades que el gobierno no debe asumir una actitud de re- celo ante la tarea crítica encomendada a la Facultad inferior, e incluso debe reconocer como necesaria e imprescindible toda indagación filosófica, cuyo fin no es otro que "descubrir la verdad en provecho de cada ciencia, y ponerla al servicio de de las $\mathrm{Fa}$ cultades superiores" (SF, Ak. VII 28). Más aún: al desarrollar la reflexión crítica en aras del progreso de las ciencias, la Facultad inferior contribuye indirectamente con los propósitos del gobierno, pues sólo a partir de un desarrollo tal podrán los gobernantes tomar nota de aquello que requiere ser modificado ${ }^{20}$. En tal sentido concluye Kant que la Facultad de Filosofía "no puede verse anclada con una interdicción del gobierno sin que éste actúe en contra de su auténtico propósito..." (SF, Ak. VII 28). En síntesis, siendo la crítica la actividad propia y esencial de la razón, es necesario que la reflexión filosófica sea eximida de toda sujeción externa. Y esto significa, ante todo, que los poderes instituidos no han de encausar la actividad de la razón hacia fines pre-establecidos, pues, como señala Kant en el Canon de la razón pura, "es algo muy absurdo esperar de la razón esclarecimiento, y prescribirle previamente, sin embargo, [en favor] de qué parte debe necesariamente resultar" (A 747/B 775).

\section{La necesidad de límites en el ejercicio crítico de la razón}

En la sección previa hemos observado que aquellos que desempeñan ciertas ocupaciones civiles deben responder ante sus respectivas Facultades y, a través de éstas, ante el gobierno, y no han de impartir ante el pueblo sino aquellas doctrinas que este último considere apropiadas para su pública difusión (hallándose, así, sujetos a las limitaciones 
inherentes al uso privado de la razón). El pueblo debe permanecer, pues, al margen de las disputas académicas, de manera tal que éstas no alienten actitudes subversivas ante los poderes instituidos:

$\mathrm{Si}$, por poner un ejemplo, los predicadores o los magistrados se dejaran llevar por el antojo de comunicar al pueblo sus reparos y dudas frente a la legislación eclesiástica o civil, le harían sublevarse con ello en contra del gobierno; en cambio, si son las Facultades, en tanto que centros de investigación, quienes se limitan a participarse mutuamente tales dudas, el pueblo no recibe prácticamente noticia alguna de todo ello, al darse por satisfecho con el reconocimiento de que semejantes sutilezas no son asunto suyo, y se siente vinculado tan sólo con cuanto le hacen saber los funcionarios comisionados por el gobierno a tal efecto. Esta libertad que, sin embargo, no cabe cercenar a la Facultad inferior, brinda el logro de que las Facultades superiores (mejor ilustradas ellas mismas) encaucen más y más por la senda de la verdad a los funcionarios, quienes a su vez, mejor instruidos asimismo acerca de su deber, acabarán por no encontrar dificultad alguna en la modificación del discurso, máxime cuando se trate únicamente de una mejor comprensión de los medios conducentes al mismo fin, algo que muy bien puede acontecer sin polémicas agresiones, que no causan sino alborotos al sistema pedagógico en curso y a la plena vigencia de sus contenidos (SF, Ak. VII, 29).

Cabría preguntarse si acaso estas observaciones referidas al presunto desinterés del pueblo por las disputas doctrinales no revelan cierta posición elitista (de hecho, no sería improbable que el pueblo mostrase algún inte- rés en "sutilezas" que afectan nada menos que a la legislación vigente, los preceptos morales y religiosos, o las cuestiones relativas a la salud pública). Sin embargo, tal vez bajo el tono peyorativo de éstas y otras observaciones kantianas referidas al pueblo ${ }^{21}$ se oculte una estrategia discursiva orientada a persuadir a los gobernantes de que la libertad de pensamiento y la libertad de expresión no resultan riesgosas para la preservación del orden social, siempre que el público en sentido amplio no resulte directamente involucrado en las disputas académicas.

Las premisas del reformismo kantiano inciden, desde luego, en esta reflexión acerca del trayecto del cambio social, cuyo punto de partida parece ubicarse en el ámbito intelectual, elevándose hasta a alcanzar la cima desde la cual se ejerce el poder político, y descendiendo, finalmente, hasta el pueblo, quien resultará beneficiado de la actividad crítica ejercida por los doctos o letrados, siempre que los gobernantes se muestren receptivos a las objeciones elevadas por estos últimos. Sólo a través de un proceso gradual las innovaciones doctrinales han de plasmarse en reformas institucionales, gracias a un espíritu de colaboración entre intelectuales y gobernantes ${ }^{22}$. Bajo tales premisas, Kant rechaza una discusión absolutamente pública (atendiendo a sus posibles consecuencias en lo que atañe a la preservación del orden civil) y se inclina por una discusión restringida a un público calificado, constituido por el universo de lectores o, en el lenguaje del escrito sobre la Facultades, por la comunidad académica ${ }^{23}$.

Quizás esta exigencia de una estricta delimitación de los ámbitos apropiados para un ejercicio legítimo de la discusión racional pueda resultar decepcionante para quienes celebran la concepción kantiana de la libertad 
de expresión como un derecho fundamental e inalienable del hombre ${ }^{24}$. Sin embargo, ha de tenerse en cuenta que los reparos de Kant ante las posibles consecuencias del uso ilimitado de la razón crítica, se fundan en un principio básico que inspira el desarrollo de su pensamiento político, a saber: la idea de que la preservación del orden jurídico es no sólo la finalidad última del Estado, sino además la condición sine qua non de la libertad civil. En la sección siguiente haremos mayor referencia a este principio y su incidencia en la exigencia kantiana de una articulación entre la libertad y la obediencia, i.e. entre un uso público y un uso privado de la razón. Por el momento, bastará con atender al modo en que esta doble exigencia -la de la libertad y la del orden- es formulada en el escrito referido al conflicto de las Facultades. Para ello han de considerarse los principios que, según establece Kant hacia el final del texto, han de regular el conflicto.

El litigio legítimo entre las Facultades no es sino la disputa que se produce como consecuencia del libre escrutinio acerca de todo tipo de doctrinas, llevado a cabo por la $\mathrm{Fa}$ cultad inferior. Dado que las doctrinas o estatutos cuya pública difusión es impuesta por el gobierno no siempre vienen a coincidir con aquello que dicta la razón, se producirá un conflicto inevitable entre las Facultades superiores y la Facultad de Filosofia, "no en tanto que una simple cuestión de competencia, sino por cuanto la Facultad inferior tiene el deber de velar por que, si bien no se diga públicamente toda la verdad, sí sea verdad todo lo que se diga y sea establecido como principio" (SF, Ak. VII, 32). Si bien no toda la verdad pueden ser públicamente expuesta, corresponde a la Facultad de Filosofía someter a examen racional el contenido de las doc- trinas impartidas por el gobierno a través de las Facultades superiores, a fin de corroborar su veracidad, y de garantizar, al menos, que no se impartan doctrinas manifiestamente falsas. El primer principio formal que ha de regular el conflicto entre las Facultades establece que tal conflicto requiere de una sentencia, "es decir, del veredicto con fuerza legal de un juez (la razón)" (SF, Ak. VII, 33). La razón constituye, así pues, juez y parte en la querella, pues sólo a ella le corresponde dictar sentencia acerca del pleito que ella mantiene con los poderes vigentes (lo cual resulta acorde, por lo demás, con la concepción kantiana de la razón como facultad que ha de llevar a cabo un constante proceso de auto-examen). El segundo principio alude, asimismo, a la función que la razón filosófica ha de desempeñar en la contienda:

dicha querella no puede cesar jamás y la Facultad de Filosofia es quien debe estar siempre en guardia a este respecto. Pues siempre se darán por parte del gobierno prescripciones estatutarias concernientes a la exposición pública de las doctrinas, dado que una libertad sin lindes para airear en público toda suerte de pareceres habría de resultar nociva tanto para el gobierno como para el propio público en general (SF, Ak. VII, 33).

Si es propio de los intereses del gobierno el dictaminar qué doctrinas han de ser públicamente impartidas, es propio de la Facultad de Filosofía renovar constantemente la discusión acerca de la racionalidad de tales doctrinas, lo cual dará origen a una contienda permanente ${ }^{25}$, de la cual han de beneficiarse no sólo las diversas ciencias sino además la sociedad en su conjunto. La exigencia de orden (elevada por el gobierno) ha de con- 
jugarse, pues, con la exigencia de libertad (elevada por la razón), instalándose así un conflicto constitutivo de la realidad políticosocial. En efecto, mientras que el gobierno "debe mantener el orden"26, la filosofía ha de velar por la verdad y por los intereses de la ciencia, para lo cual requiere de una absoluta independencia respecto de toda prescripción gubernamental. $Y$ en este ejercicio filosófico, crítico y racional, se cifra, en última instancia, la factibilidad de un progreso de las instituciones sociales. El conflicto entre el imperativo del orden y la exigencia de libertad resulta, así pues, no sólo inevitable sino, además, necesario.

En la formulación del segundo principio, Kant no sólo hace hincapié en la necesidad de que el gobierno conceda plena autonomía a la Facultad de Filosofia, sino que insiste asimismo en la exigencia de que la filosofía no abandone su examen crítico:

todo precepto gubernamental, al provenir de hombres o, cuando menos, verse sancionado por ellos, no deja de hallarse expuesto al peligro del error o de los efectos contraproducentes; y la sanción del gobierno por lo que atañe a las Facultades superiores no supone una excepción a esa regla. Por ello la Facultad de Filosofia no puede dejar de blandir sus armas contra el peligro con que se ve amenazada la verdad, cuya custodia le ha sido encomendada, habida cuenta de que las Facultades superiores nunca renunciarán a su afán de dominio (SF, Ak. VII, 33).

El tercer principio que ha de regular la contienda entre las Facultades establece que "este litigio no tiene por qué perjudicar al gobierno en ningún caso", y éste debe, por consiguiente, consentirlo e incluso promoverlo. El gobierno puede exigir a las Facultades superiores que impartan determinadas doctrinas; sin embargo, todo cuanto les atañe en tanto comunidades cientificas ha de permanecer ajeno a sus preceptos ${ }^{27}$.

En la formulación de este tercer principio, no sólo se exige que el gobierno no ponga obstáculos a la contienda y garantice plena autonomía a la Facultad de Filosofía, sino que se indica además que incluso los miembros de las Facultades superiores deben gozar de cierta autonomía, por cuanto éstas

no tienen que responder ante el gobierno sino de la instrucción que imparten públicamente a su clientela, ya que tal actividad incide en el público en cuanto sociedad civil y queda por ello bajo la sanción del gobierno, dado que podría dañar la influencia de éste sobre aquélla. Otra cosa muy distinta son las doctrinas y opiniones que las Facultades convienen entre sí bajo la denominación de teorías, pues ese intercambio tiene lugar entre otra clase de público, cual es el conformado por la comunidad académica que se ocupa de bregar con las ciencias; el pueblo se resigna a no comprender nada de todo ello y el gobierno, por su parte, no considera conveniente entrometerse en las disputas académicas (SF, Ak. VII, 34).

Particularmente interesante resulta la distinción que aquí se establece entre dos clases de público, a saber: el público "conformado por la comunidad académica" y "el público en cuanto sociedad civil" ${ }^{\prime 28}$. Aquél podría ser caracterizado como un tribunal de la razón, por oposición a este último, al que Kant caracteriza, en una nota a pie de página, como el tribunal del pueblo (ante el cual no resultaría prudente exponer los detalles de la contienda): 
En cambio, si se trasladara el conflicto a la comunidad civil (verbigracia a los púlpitos) [...], dicho conflicto se vería presentado sin permiso ante el tribunal del pueblo (al que no compete emitir juicio alguno en el terreno académico) y dejaría de ser una controversia científica; dándose así lugar a esa querella ilegítima mencionada anteriormente, donde la exposición de las doctrinas se adapta a las inclinaciones del pueblo y se disemina el germen de la revuelta y de las facciones, poniendo en peligro al gobierno. Quienes se erigen arbitrariamente a sí mismos en tribunos del pueblo renuncian con ello a la condición de sabios, atentan contra los derecho de la constitución civil $[\ldots]$ y son propiamente neólogos [...]. $[\mathrm{P}]$ romueven una forma de gobierno totalmente distinta o más bien una total ausencia del mismo (anarquía) y remiten el dictamen sobre cuestiones académicas al pueblo, cuyo juicio manejan gracias a sus costumbres, sentimientos e inclinaciones, cobrando así ventaja sobre la influencia de un gobierno legítimo (SF, Ak. VII, 34).

En la formulación de este tercer principio aparece, pues, claramente expresado el criterio básico que permite establecer la legitimidad de la contienda entre las Facultades: la contienda será legítima en tanto se desarrolle dentro de los límites de lo que en el escrito sobre la ilustración ha sido caracterizado como el uso público de la razón; por el contrario, la contienda será ilegítima en caso de que rebase los márgenes de la institución académica e involucre al pueblo, "poniendo en peligro al gobierno"29. Quienes participen al pueblo de la disputa, manipulando los intereses de éste a fin de desestabilizar el orden público, incurren en una querella que no puede desembocar sino en la anarquía, comprometiendo así la propia subsistencia del orden civil.

Finalmente, un cuarto principio establece que "esta querella puede perdurar hasta que se logre un acuerdo entre la comunidad académica y la sociedad civil en materia de máximas cuya observancia ha de propiciar en ambas clases de Facultades un progreso continuo hacia una mayor perfección y abolir, finalmente, cualquier tipo de restricción que el gobierno pretenda imponer a la libertad" (SF, Ak. VII, 35). Esta observación sugiere que la libertad constituye el medio y, a la vez, el fin de un proceso orientado hacia un estado de mayor perfección (un estado en el que la libertad pueda ser ejercida sin restricciones). Mientras nos aproximamos a una constitución republicana-fundada en los principios de la libertad, la igualdad y la independencia civil${ }^{30}$, la libertad ha de ejercida, sin embargo, dentro de límites institucionales precisos, con la esperanza de que estos límites resulten progresivamente disueltos, haciéndose finalmente innecesarias las limitaciones de la libertad. Así como en el escrito acerca de la Ilustración Kant se rehúsa a caracterizar su propia época como una época ilustrada, señalando, sin embargo, que "vivimos en una época de ilustración", pues -señala- existen indicios que revelan una mayor libertad, a través de la cual serán progresivamente superados los obstáculos para una ilustración general (cf. WA, Ak. VIII; 40), así también parece concebir la contienda legítima entre las Facultades como el signo de un progreso hacia un estado de mayor perfección. El medio fundamental del cual debemos servirnos para contribuir a la realización de esa meta no es sino la libertad de pensamiento (ejercitada, no obstante, dentro de límites preestablecidos), pero ella constituye, a la vez, el fin 
último del proceso, orientado -como hemos señalado-hacia una constitución política fundada en el principio de la libertad. La libertad trabaja, pues, en pos de sí misma (al igual que la razón, que sólo puede verse beneficiada en tanto responda a sus intereses propios).

\section{La exigencia de una articulación entre la} libertad y el orden en el escrito sobre las Facultades. Consideraciones finales acerca del orden como condición sine qua non del Estado de derecho

Hemos señalado que la contienda entre las Facultades ha de desarrollarse como una contienda académica (sin que ello implique, desde luego, desconocer las insoslayables proyecciones políticas de semejante contienda). El uso público de la razón (referido, en el escrito de 1798, a aquellos que se dirigen, en tanto doctos, al universo de lectores) resulta restringido, en este caso, a un público conformado por la comunidad filosófica. La Facultad de Filosofía realiza una tarea imprescindible, cual es la de examinar críticamente (a la luz de la pura razón) las doctrinas públicamente impartidas por las Facultades superiores, a fin de señalar lo que en tales doctrinas pudiese haber de erróneo o inconveniente, contribuyendo así con los propios fines del gobierno. El objetivo final de la querella entre las Facultades no es, pues, sino el perfeccionamiento gradual de las instituciones jurídico- políticas, hacia una constitución en la que pueda ser factible un mayor grado de libertad.

Si bien el gobierno ha de conceder absoluta libertad a la razón a fin de que ésta pueda desempeñar la tarea crítica que le es propia, esta libertad ha ser de ejercida dentro de límites precisos, de manera tal que no atente contra la autoridad del gobierno, generando el desorden y la anarquía. Ahora bien, si la libertad es no sólo un derecho básico y fundamental del hombre sino, a la vez, la condición última de todo progreso histórico, el orden es, por su parte, una condición igualmente fundamental, ya que el Estado tiene por finalidad última garantizar la subsistencia del orden jurídico, en cuyo marco el ejercicio de la libertad puede ser efectivamente garantizado. La libertad y el orden constituyen, así pues, desde la perspectiva kantiana, dos condiciones básicas e igualmente necesarias del progreso $(\mathrm{y}$ la tensión que se produce entre estas dos exigencias no puede ser suprimida, sino que ha de ser encausada, en todo caso, a través de canales institucionales, por medio de los cuales puedan ser promovidas las reformas necesarias en la constitución vigente). Si bien Kant parece abrigar la esperanza de que en el futuro las restricciones impuestas al uso público de la razón sean menores, otros pasajes sugieren que la tensión entre la razón crítica y el poder político es insuperable y constitutiva del orden socio-político ${ }^{31}$. En todo caso, y más allá de que se identifique a Kant como un claro exponente del optimismo ilustrado, o bien se lo considere como un autor ligado a ciertas formas del realismo político, es posible afirmar que la exigencia de preservar el orden asume una importancia decisiva en el desarrollo de su pensamiento político, no porque el orden sea antepuesto a la libertad, sino antes bien porque aquél es asumido como una condición básica para el ejercicio de la libertad. Ésta es, pues, la premisa básica subyacente en esta exigencia incondicionada de preservar el orden y evitar la resistencia ante los poderes instituidos (incluso en aquellos casos en los que la libertad y el derecho resultasen comprometidos). Los pasajes siguientes expresan 
de manera sucinta esta premisa básica y recurrente en el desarrollo del pensamiento político kantiano:

[E]l poder que en el Estado da efectividad a la ley no admite resistencia (es irresistible), y no hay comunidad jurídicamente constituida sin tal poder, sin un poder que eche por tierra toda resistencia interior, pues ésta acontecería conforme a una máxima que, universalizada, destruiría toda constitución civil, aniquilando el único estado en que los hombres pueden poseer derechos en general (TP, Ak. VIII, 299, nuestro subrayado).

La salud pública que se ha de tomar en consideración ante todo es precisamente aquella constitución legal que garantiza a cada uno su libertad por medio de leyes (TPAA. VIII, 298).

La razón por la que el pueblo debe soportar, a pesar de todo, un abuso del poder supremo, incluso un abuso considerado intolerable, es que su resistencia a la legislación suprema misma ha de concebirse como contraria a la ley, incluso como destructora de la constitución legal (RL, Ak. VI, 320, nuestro subrayado).

Cualquier constitución jurídica, conforme al derecho aunque sea en pequeño grado, es mejor que ninguna (ZeF, Ak. VIII, 373).

He aquí, pues, el argumento básico implícito en la exigencia kantiana de una estricta delimitación del ámbito en el que ha de otorgarse a la razón una absoluta libertad para el logro de sus fines propios y esenciales: el orden es la condición fundamental para la subsistencia del Estado de derecho, único estado en el que puede ser garantizado el ejercicio de los derechos humanos fundamentales ${ }^{32}$.
Sin orden, no es factible el ejercicio de nuestro derecho innato a la libertad. De allí que una interrogación acerca de cuál de estos principios (libertad y orden) cobra primacía en el pensamiento kantiano no resulte, a fin de cuentas, pertinente, puesto que se trata aquí de principios indisolublemente vinculados, cuya articulación resulta necesaria a fin de garantizar el progreso y la ilustración del género humano. Si bien es preciso reconocer la relación de tensión que suele darse entre ambos principios en el tratamiento kantiano de diversos problemas político-jurídicos, quizás resulte más fructífero, para el estudioso del pensamiento político-jurídico kantiano, reparar en los principios doctrinales que subyacen a esta tensión (principios que inciden, desde luego, en la posición asumida por Kant respecto de la posibilidad de un derecho de resistencia, en su tratamiento del principio de soberanía, o en su reflexión acerca del derecho de ciudadanía) ${ }^{33}$.

Hacia el final del escrito sobre la Ilustración, Kant admite que el decurso de los asuntos humanos resulta ciertamente paradójico: en efecto, "un mayor grado de libertad civil parece provechosa para la libertad espiritual del pueblo y, pese a ello, le coloca límites infranqueables; en cambio un grado menor de esa libertad civil procura el ámbito para que esta libertad espiritual se despliegue con arreglo a toda su potencialidad" (WA, Ak. VIII, 41). En La contienda de las Facultades, formula un principio igualmente paradojal, a saber: aquel que establece que la razón ha de ser ejercida de manera $a b$ solutamente libre, mas dentro de límites estrictamente determinados ${ }^{34}$. Sólo bajo una condición tal puede ser garantizado un desarrollo fértil de la reflexión filosófica, evitándose "el germen de la revuelta y de las fac- 
ciones" ${ }^{\prime 35}$, que hace peligrar la estabilidad del orden vigente amenazando así la continuidad de condiciones institucionales que posibilitan el pleno ejercicio de nuestros derechos fundamentales y el desarrollo óptimo de nuestras disposiciones naturales.

\section{REFERENCIAS BIBLIOGRÁFICAS}

Abellán, Joaquín (1996), “En torno al concepto de ciudadano en Kant: comentario de una aporía", en: Rodríguez Aramayo, R., Muguerza, J., Roldán, C. (comps.), La paz y el ideal cosmopolita de la Ilustración. A propósito del bicentenario de Hacia la paz perpetua de Kant, Madrid, Tecnos, pp. 239-258.

Aramayo, Roberto R. (1993), "Los dos ejemplos paradigmáticos del rigorismo jurídico de Kant", estudio preliminar del texto: Kant, Immanuel, Teoría y práctica, Madrid, Tecnos, 1993, pp. X-xxvii.

Aramayo, Roberto R. (2001a), "Kant y la ilustración”, Isegoría, 25, pp. 293-309.

Aramayo, Roberto R. (2001b), Immanuel Kant. La utopía moral como emancipación del azar, Buenos Aires, Edaf.

Astorga, Omar (1998), "Principales tendencias interpretativas sobre la influencia del modelo hobbesiano en el pensamiento político de Kant", Episteme, XVIII, 3, pp. 3-12.

Atkinson, Ronald (1992), "Kant's Moral and Political Rigorism", en: Williams, H. (ed.), Essays on Kant's Political Philosophy, United Kindom, The University of Chicago Press, pp. 228-248.

Beade, Ileana (2007), "Liberalismo y republicanismo en la concepción kantiana de 'ciudadano"'. Reflexión política (Colombia), 9, 17, pp. 58-74.
Beade, Ileana (2009) "Consideraciones acerca de la concepción kantiana de la libertad en sentido político". Revista de Filosofia (Universidad de Chile), 65, pp. 25-42.

Beade, Ileana (2011a), "Libertad y naturaleza en la filosofía kantiana de la Historia". Daimon, 54, pp. 25-44.

Beade, Ileana (2011b), "Educación y progreso. Una mirada desde la reflexión pedagógica kantiana", Signos Filosóficos, 13, 25, pp. 101-120.

Beade, Ileana (2012), "Ciudadanos activos y pasivos. Un análisis crítico de las reflexiones kantianas acerca del derecho de ciudadanía", Revista de Filosofia (México). 132, pp. 83-104.

Beade, Ileana (2013), "El concepto kantiano de voluntad pública y su relación con la noción rousseauniana de voluntad general", Estudios kantianos (Brasil), 1.2, pp. 59-84.

Beade, Ileana (2014), "La impugnación del derecho de resistencia en el marco de la Filosofia kantiana del Derecho", en Caimi, M. (ed.), Temas kantianos, Buenos Aires, Prometeo, pp. 259-294.

Berlin, Isaiah (1992), "Dos conceptos de la libertad", en Quinton, A. (comp.), Filosofia política, México, Fondo de Cultura Económica, pp. 216-233.

Bertomeu, María Julia (2005), "Las raíces republicanas del mundo moderno: en torno a Kant", en Bertomeu, M. J., Doménech, A. F. (comps.), Republicanismo y democracia, Buenos Aires, Miño y Dávila.

Bielefeldt, Heiner (1997), “Autonomy and Republicanism: Immanuel Kant's Philosophy of Freedom", Political Theory, 25,5 , pp. 524-558. 
Bobbio, Norberto (1995), Igualdad y libertad, traducción de P. Aragón, Madrid, Paidós.

Clarke, Michael (1997), "Kant's Rhetoric of Enlightenment", The Review of Politics, 59, 1, pp. 53-73.

Colomer, José Luis (1994), "Algunos apuntes sobre Kant y la libertad política", Doxa, 15-16, pp. 581-594.

Cronin, Ciaran (2003), "Kant's Politics of Enlightenment", Journal of the History of Philosophy, 41, 1, pp. 51-80.

Davis, Kevin (1992), "Kant's different Publics and the Justice of Publicity", KantStudien, 83, pp. 170- 184.

Deligiorgi, Katerina (2002), "Universability, Publicity, and Communication: Kant's Conception of Reason", European Journal of Philosophy, 10, 2, pp. 143-159.

Deligiorgi, Katerina (2005), Kant And The Culture Of Enlightenment, New York, State University of New York Press.

Dotti, Jorge (1985), "Kant: crítica y modernidad", Punto de vista. Revista de cultura, 23, pp. 29-34.

Dotti, Jorge (2005), “Observaciones sobre Kant y el liberalismo", Araucaria, 6, 13, pp. 3-17.

Dreier, Horst (2005), "Kant's Republik", en Gerhardt, V. (ed.), Kant im Streit der Fakultäten, Berlin, De Gruyter, pp. 134-170.

Gómez Caffarena, José (1999), "Estudio preliminar", en: Kant, I., La contienda entre las facultades de filosofia y teología, traducción de Roberto Rodríguez Aramayo, Madrid, Trotta, pp. ix-lxix.

González Vicén, Felipe (1952), La filosofia del estado en Kant, San Cristóbal de la Laguna, 1952.

Guyer, Paul (2006), Kant, Routledge, New York.
Hancock, Roger (1975), "Kant and Civil Disobedience", Idealistic Studies, 5, pp. 164-176.

Hindrichs, Gunnar (2009), "Die aufgeklärte Aufklärung", en: Klemme, H. (ed.), Kant und die Zukunft der europäischen Aufklärung, Berlin, De Gruyter, pp. 43-67. Hinske, Norbert (1981), "Einleitung", in N. Hinske (ed.), Was ist Aufklärung? Beiträge aus der Berlinischen Monatsschrift, Darmstadt, pp. xiii-lxix.

Hutter, Axel (2009), "Kant und das Projekt einer Metaphysik der Aufklärung", in: $\mathrm{H}$. Klemme (ed.), Kant und die Zukunft der europäischen Aufklärung, Berlin, Walter De Gruyter, pp. 68-81.

Jüngel, Eberhard (2005), "Der Mensch im Schnittpunkt von Wissen, Glauben, Tun und Hoffen. Die theologische Fakultät im Streit mit der durch Immanuel Kant repräsentierten philosophischen Fakultät", en: Gerhardt, V. (ed.), Kant im Streit der Fakultäten, Berlin, De Gruyter, pp. 1-38.

Kant, Immanuel (1902ss.), Kant's gesammelte Schriften, hrsg. von der Königlich Preussischen, bzw. der Deutschen Akademie der Wissenschaften, Berlín et alia.

Kant, Immanuel (1993), Teoría y práctica [Über den Gemeinspruch: Das mag in der Theorie richtig sein taugt aber nicht für die Praxis, 1793], traducción de M. Palacios, F. Pérez López y R. Rodríguez Aramayo, Madrid, Tecnos.

Kant, Immanuel (1994), Ideas para una Historia Universal en clave cosmopolita y otros escritos sobre Filosofia de la Historia [Idee zu einer allgemeinen Geschichte in weltbürgerlicher Absicht, 1784], traducción de. C. Roldán Panadero y R. Rodríguez Aramayo). Madrid, Tecnos. 
Kant, Immanuel (1994), Metafisica de las costumbres [Die Metaphysik der Sitten, 1797], traducción de Adela Cortina Orts y Jesús Conill Sancho, Madrid, Tecnos.

Kant, Immanuel (1996), Sobre la paz perpetua [Zum ewigen Frieden, 1795], traducción de J. Abellán, Madrid, Tecnos.

Kant, Immanuel (2004), "Contestación a la pregunta: ¿Qué es la Ilustración?” $[B e-$ antwortung der Frage: Was ist Aufklärung?], en Kant, I., Qué es la Ilustración, edición y traducción de R. Rodríguez Aramayo, Madrid, Alianza, pp. 83-93.

Kant, Immanuel (2005), ¿Cómo orientarse en el pensamiento? [Was heisst: Sich im Denken orientieren?, 1786], traducción de C. Correa, Buenos Aires, Quadrata.

Kant, Immanuel (2007), Crítica de la razón pura [Kritik der reinen Vernunft, 1781/1787] traducción de M. Caimi, Buenos Aires, Colihue.

Kaufman, Arthur (1997), "Reason, Self-legislation and Legitimacy: Conceptions of Freedom in the Political Thought of Rousseau and Kant", The Review of Politics, 59, 1, pp. 25-52.

Kersting, Wolfgang (1999), "Politics, freedom, and order: Kant's political philosophy", en Guyer, P. (ed.), The Cambridge Companion to Kant, New York, Cambridge University Press.

Kersting, Wolfgang (2007), Wohlgeordnete freiheit. Immnuel Kants Rechts und Staatsphilosophie, Paderborn, Mentis Verlag.

La Rocca, Claudio (2006), "Kant y la Ilustración”, Isegoría, 35, pp. 107-127.

La Rocca, Claudio (2009), "Aufgeklärte Vernunft-Gestern und Heute", en: Klemme, H. (ed.), Kant und die Zukunft der europäischen Aufklärung, Walter De Gruyter, Berlin, pp. 100-123.
Laursen, John (1986), "The Subversive Kant: The Vocabulary of 'Public' and 'Publicity"', Political Theory 14, 4, pp. 584-603.

Letistion, Steven (1993), "Kant and the End of Enlightenment in Prussia", Journal of Modern History, 65, pp. 57-112. Mittelstraß, Jürgen (2005), "Der Streit der Fakultäten und die Philosophie", en: Gerhardt; V. (ed.), Kant im Streit der Fakultäten, Berlin, pp. 39-60.

Mulholland, Leslie (1990), Kant's System of Rights. New York, Columbia University Press.

Nicholson, Peter (1976), "Kant on the Duty Never to Resist the Sovereign", Ethics, 86, 3, pp. 214-230.

Nicholson, Peter (1992), "Kant, Revolutions and History", en: Williams, H., (ed.), Essays on Kant's Political Philosophy, United Kindom, pp. 249-268.

Pettit, Philip (2004a), Republicanismo. Una teoría sobre la libertad y el gobierno, traducción de Toni Domènech, Barcelona, Paidós.

Pettit, Philip (2004b), "Liberalismo y republicanismo", en: Ovejero, F.; Martí, J. L., Gargarella R. (comps.), Nuevas ideas republicanas. Autogobierno y libertad, Barcelona, Paidós, pp. 115-135.

Pievatolo, Maria C. (1999), "The tribunal of Reason: Kant and the Juridical Nature of Pure Reason", Ratio Juris 12, 3, pp. 311-327.

Pinkard, Terry (1999), "Kant, Citizenship, and Freedom (§§41-52)", en Höffe, O. (ed.), Metaphysische Anfangsgründe der Rechtslehre, Berlin, pp. 155-172. Recki, Birgit (1998), "Der Kanon der reinen Vernunft: «...nichts mehr, als zwei Glaubensartikel»?", en: Mohr, G.; Willaschek, 
M. (eds.), Klassiker Auslegen. Immanuel Kant: Kritik der reinen Vernunft, Berlin, Akademie Verlag, pp. 611-615.

Ripstein, Arthur (2009), Force and Freedom.

Kant's Legal and Political Philosophy,

Cambridge, Cambridge University Press.

Schdmidt, James (1989), "The Question of

Enlightenment: Kant, Mendelssohn, and

the Mittwochsgesellschaft", Journal of the

History of Ideas, 50, pp. 269-291.

Schdmidt, James (1992), "What Enlighten-

ment Was: How Moses Mendelssohn and

Immanuel Kant Answered the Berlinische Monatsschrift', Journal of the History of Philosophy, 30, pp. 77-101.

Scholz, Oliver (2009), “Kants Aufklärungsprogramm: Rekonstruktion und Verteidigung", en: Klemme, H. (ed.), Kant und die Zukunft der europäischen Aufklärung, Berlin, Walter De Gruyter, pp. 28-42.

Skinner, Quentin (2005), "La libertad de las repúblicas: ¿un tercer concepto de libertad?", Isegoría, 33, pp. 19-49.

Timmermann, Jens (2005), "Kants ,Streit“ und die Universität von morgen”, en: Gerhardt, V. (ed.), Kant im Streit der Fakultäten, Berlin, Walter De Gruyter, pp. 61-83.
Velasco Gómez, Ambrosio (2005), "La concepción republicana de Kant”, Episteme, 25, 2, pp. 109-122.

Villacañas Berlanga, José L. (1987), Racionalidad crítica. Introducción a la Filosofia de Kant, Madrid, Tecnos.

Vos, Rein (2008), "Public Use of Reason in Kant's Philosophy: Deliberative or Reflective?, en: V. Rohden, V.; Terra, G. de Almeida, R.; Ruffing, M. (eds.), Akten des $X$. Internationales Kant-Kongress, Berlin, De Gruyter, pp. 753-763.

Williams, Howard (2001), "Metamorphosis or Palingenesis? Political Change in Kant", The Review of Politics, 63, 4, pp. 693-722.

Williams, Howard (1983), Kant 's Political Philosphy, Oxford, Basil Blackwell.

Wit, Ernst (1999), "Kant and the Limits of Civil Obedience", Kant-Studien, 90, pp. 285-305.

Zöller, Günter (2009), “Aufklärung über Aufklärung. Kants Konzeption des selbständigen, öffentlichen und gemeinschaftlichen Gebrauchs der Vernunft", en: Klemme, H. (ed.), Kant und die Zukunft der europäischen Aufklärung, Berlin, De Gruyter, pp. 82-99.

\section{NOTAS}

${ }^{1}$ Cf. Der Streit der philosophischen Facultät mit der theologischen (SF), Ak. VII, 15-75. La paginación citada corresponde a la edición académica de las obras kantianas: Kant's gesammelte Schriften, hrsg. von der Königlich Preussischen, bzw. der Deutschen Akademie der Wissenschaften, Berlín et alia, 1902 ss., I-IX. A esta edición aludimos bajo la abreviatura Ak., seguida del número de tomo, indicado en números romanos.

${ }^{2}$ Kant propone en este breve ensayo una respuesta a la pregunta qué es la ilustración, inscribiéndose así en un debate que convocó a importantes figuras de la intelectualidad europea, ya en los albores del período ilustrado, y se prolonga incluso hasta el presente (cf. La Rocca, 2006, 108). En los círculos de la ilustración alemana, la pregunta acerca del sentido de la Ilustración encuentra un punto de inflexión clave en la formulación propuesta por J. F. Zöllner, quien en un artículo de 1783 publicado en la Berlinische Monatsschrift, señala que esta pregunta, pese a su importancia, no ha hallado aún una respuesta satisfactoria. La interrogación formulada por Zöllner impulsará una intensa discusión acerca de la naturaleza, el alcance y los límites de la Ilustración, discusión en cuyo marco intentarán dilucidarse las consecuencias morales, políticas y culturales del proyecto ilustrado (cf. Cronin, 2003, 60-69; Hinske, 1981, xiii ss.; Schmidt, 1992, 77-101; Laursen, 1996, 253-269; Lestition, 1993, 57-112; Zöller, 2009, 82-89; Scholz, 2009, 30; Hutter, 2009, 68). Como La Rocca ha señalado, el concepto kantiano de ilustración no sólo asume un sentido claramente po- 
Libertad y orden en la Filosofía política kantiana. Acerca de los límites del uso público de la razón...

lítico e histórico, sino asimismo una significación más amplia, esencialmente conectada con su concepción de la razón y su programa de una filosofía crítica (cf. La Rocca, 2009, 100-101). Vid. asimismo: Hindrichs, 2009, 43-44.

${ }^{3}$ Cf. WA, Ak. VIII, 36-37.

${ }^{4}$ Cf. Über den Gemeinspruch: Das mag in der Theorie richtig sein, taugt aber nicht für die Praxis (TP), Ak. VIII, 299.

${ }^{5}$ Tras definir la Ilustración como la superación de un estado de minoría de edad caracterizado, básicamente, por la incapacidad de un individuo de servirse de su propio entendimiento (cf. WA, Ak. VII, 35-36), Kant señala que para la promoción de la Ilustración "tan sólo se requiere libertad y, a decir, verdad, la más inofensiva de cuantas pueden llamarse así: el hacer uso público de la propia razón en todos los terrenos. Actualmente oigo clamar por doquier: ¡No razones, adiéstrate! El asesor fiscal: ¡no razones y limítate a pagar tus impuestos! El consejero espiritual: ¡No razones, ten fe! [...]. Impera por doquier una restricción de la libertad. Pero ¿cuál es el límite que la obstaculiza y cuál es el que, bien al contrario, la promueve? He aquí mi respuesta: el uso público de su razón tiene que ser siempre libre y es el único que puede procurar ilustración entre los hombres; en cambio muy a menudo cabe restringir su uso privado, sin que por ello quede particularmente obstaculizado el progreso de la ilustración. Por uso público de la propia razón entiendo aquél que cualquiera puede hacer, como alguien docto, ante todo el público que configura el universo de los lectores. Denomino uso privado al que cabe hacer de la propia razón en una determinada función o puesto civil, que se le haya confiado" (WA, Ak. VIII, 36-37).

${ }^{6}$ Para un análisis de las circunstancias históricas particulares que incidieron en la elaboración y publicación de este escrito, vid. Gómez Caffarena, 1999, xx ss.; Aramayo, 2001a, 301-304.

${ }^{7}$ En TP se refiere Kant de manera explícita a esta finalidad propia y característica del Estado al señalar que "no se trata [...] de la felicidad que al súbdito le cabe esperar de una situación o del gobierno de la comunidad, sino simplemente, $y$ ante todo, del derecho que por ese medio debe ser garantizado a cada uno: este es el principio supremo del que han de emanar todas las máximas que conciernen a una comunidad, principio que no está limitado por ningún otro" (TP, Ak. VIII, 298, nuestro subrayado). Señala Aramayo al respecto que "[1]a misión del Estado no es la de procurar felicidad, sino establecer un marco de convivencia en el que todos los ciudadanos puedan ejercitar su libertad" (Aramayo, 2001b, 113-114).

${ }^{8}$ En la Crítica de la razón pura [Kritik der reinen Vernunft (KrV), 1781/1787], Kant describe el estado de naturaleza como "un estado de injusticia y de violencia", y advierte que "necesariamente se lo debe abandonar para someterse a la coacción de la ley, que limita nuestra libertad sólo para que pueda ser compatible con la libertad de cada uno de los otros, y precisamente por ello, [pueda ser compatible] con el bien común" (KrV, A 752/B 780). En los Principios metafisicos del derecho [Metaphysische Anfangsgründe der Rechtslehre (RL), 1797], Kant caracteriza el estado de naturaleza como un estado en el que sólo puede darse una libertad "salvaje y sin ley", estado que debe ser superado a través de la institución de un orden civil, en cuyo marco la libertad pueda ser garantizada bajo leyes públicas de carácter coactivo (cf. RL, Ak. VI, 315-316). La teoría kantiana del contrato establece el deber práctico de abandonar el estado de naturaleza, en el cual los derechos naturales (innatos) del hombre no pueden ser sino provisorios, y su ejercicio, meramente contingente (cf. [Referencia personal 8]). Si bien esta tesis permite inscribir a Kant en la corriente del iusnaturalismo moderno, ha sido señalado que los principios iusnaturalistas convergen, en sus escritos políticojurídicos, con premisas que podrían considerarse afines al positivismo jurídico. Sobre esta cuestión, vid. Villey, 1962: 58-66; Kersting, 2007, 390ss.; Cortina Orts, 1994, xliii-xlvi; Hancock 1961, 440-447.

${ }^{9}$ Cf. González Vicén, 1952, 50-52, 95s.

${ }^{10} \mathrm{Cf}$. SF, Ak. VII, 20, 28.

${ }^{11}$ Cf. SF, Ak. VII, 19-20, 32. En esta contienda política, las Facultades superiores desempeñan una función de mediación fundamental entre el pueblo y el gobierno, pues éste ejerce influencia sobre aquél a través de sus ministros o funcionarios, que a su vez responden ante dichas Facultades. El control que el Estado necesita ejercer sobre el pueblo a fin de garantizar el orden público se articula, así pues, institucionalmente, a través de instancias mediadoras, cuya sujeción a los estatutos gubernamentales resulta decisiva.

${ }^{12}$ Para un análisis de la función específica encomendada a la Facultad de Filosofía en el marco de la contienda, vid. Mittelstraß, 2005, 49-50; Jüngel, 2005, 24; Timmermann, 2005, 69-72.

${ }^{13} \mathrm{Cf}$. Aramayo, 2001a, 298.

${ }^{14}$ No hay consenso entre los intérpretes respecto del sentido específico que ha de atribuirse a la noción kantiana de uso privado de la razón: mientras algunos proponen interpretarla en relación con cierta relación contractual en virtud de la cual los individuos renuncian a hacer un libre uso de sus facultades y capacidades a fin de que el orden público pueda ser preservado, contribuyendo así al logro de ciertas metas comunes (vid. Schmidt, 1989, 288; Cronin, 2003, 59; Vos, 2008, 760-763; Bartuschat, 2009, 14), otros, como O'Neill, sugieren, que tal uso de la razón es calificado como privado en el sentido de deficiente, es decir, como un uso de la razón privado de libertad (cf. Vos 756ss.).

${ }^{15}$ Cabe señalar que en ambos escritos sólo se deniega libertad a quienes desempeñan ciertas funciones civiles en tanto que desempeñan tales funciones: en efecto, tanto los 
miembros de las Facultades superiores como los funcionarios del gobierno se hallan autorizados, en su carácter de $d o c$ tos, a reflexionar libremente acerca del contenido de las doctrinas impartidas ante el pueblo, siempre que tales especulaciones no sean difundidas ante el público en general (cf. SF, Ak. VII, 34).

16 "El conjunto de las Facultades superiores (ala derecha del parlamento de la ciencia) defiende los estatutos del gobierno, pero en una constitución tan libre como ha de ser aquella que se erija en aras de la verdad, debe haber también un partido opositor (el ala izquierda), cuyos escaños corresponden a la Facultad de Filosofía, ya que sin contar con el severo examen y las críticas de ésta el gobierno no se hallaría satisfactoriamente informado respecto de aquello que puede resultarle ventajoso o perjudicial" (SF, Ak. VII, 35).

${ }^{17}$ Cf. Beade, 2011a, 25-44; Beade, 2011b, 101-120.

${ }^{18}$ Para un análisis del contenido temático de esta sección de la Doctrina trascendental del método, vid, Recki, 1998.

19 "Siempre es útil, sin la menor duda, dar completa libertad a la razón que investiga y que examina, para que pueda cultivar sin trabas su propio interés, que resulta tan favorecido si se imponen limitaciones a su conocimiento, como si se lo ensancha; y que siempre resulta menoscabado si intervienen manos ajenas para dirigirla de acuerdo con propósitos forzados, en contra de su marcha natural" (A 744/B 772). Más adelante, señala Kant: "La razón, en todas sus empresas, debe someterse a la crítica, y no puede menoscabar la libertad de ésta con ninguna prohibición, sin perjudicarse a sí misma y sin atraer sobre sí una sospecha que le es desfavorable. No existe nada tan importante, en lo que toca al provecho, nada tan sagrado, que pueda sustraerse a esta inspección que controla y que examina, y que no conoce acepción de personas. En esa libertad se basa incluso la existencia de la razón, que no tiene autoridad dictatorial, sino que la sentencia de ella es siempre sólo el consenso de ciudadanos libres, cada uno de los cuales debe poder expresar sin reservas sus escrúpulos e incluso su veto" (A 738-739/B 766-767). La libertad en la evaluación crítica de todo tipo de doctrinas es, pues, la condición necesaria para que la razón pueda dictar sentencia sobre los asuntos que le incumben en sentido más propio. Para un análisis del sentido jurídico que Kant atribuye a la actividad crítica de la razón, vid. Pievatolo, 1999.

${ }^{20} \mathrm{Ha}$ de señalarse, sin embargo, que las proyecciones políticas implicadas en la actividad crítica llevada a cabo por la razón son, en todo caso, indirectas: en efecto, es necesario que el ejercicio de la crítica sea absolutamente autónomo, esto es, que no atienda a intereses políticos determinados, sino únicamente a principios racionales inmanentes. El filósofo no ha de atender, pues, a cuestiones de orden político en el desarrollo de sus indagaciones; las consecuencias o proyecciones políticas que pudiesen acarrear tales indagaciones dependerán, en última instancia, de que los gobernantes den acogida a las objeciones elevadas por los filósofos, adoptándolas como principios que han de regular la implementación de modificaciones necesarias en la constitución vigente. En tal sentido señala Kant, en Hacia la paz perpetua [Zum ewigen Frieden (ZeF), 1795]: "No hay que esperar que los reyes filosofen ni que los filósofos sean reyes, como tampoco hay que desearlo, porque la posesión del poder daña inevitablemente el libre juicio de la razón. Pero es imprescindible para ambos que los reyes, o los pueblo soberanos (que se gobiernan a sí mismos por leyes de igualdad), no dejen desaparecer o acallar a la clase de los filósofos sino que los dejen hablar públicamente para aclaración de sus asuntos, pues la clase de los filósofos, incapaz de banderías y alianzas de club por su propia naturaleza, no es sospechosa de difundir una propaganda" (ZeF, Ak. VIII, 369).

${ }^{21} \mathrm{Cf}$. SF, Ak. VII, 35. En En torno al tópico: «Tal vez eso sea correcto en teoría, pero no sirve para la práctica» [Über den Gemeinspruch: Das mag in der Theorie richtig sein, taugt aber nicht für die Praxis (TP), 1793], señala Kant: "En toda comunidad tiene que haber una obediencia sujeta al mecanismo de la constitución estatal, con arreglo a leyes coactivas (que conciernen a todos), pero a la vez tiene que haber un espiritu de libertad, pues en lo que atañe al deber universal de los hombres todos exigen ser persuadidos racionalmente de que tal coacción es legítima [...]. Porque la intercomunicación es una vocación natural de la humanidad [...]. Y, además, ¿porqué otro medio podría el gobierno alcanzar los conocimientos que favorecen su propia intención esencial, si no es dejando que se exprese este espíritu de libertad, tan digno de respeto en su origen y en sus efectos?" (TP, Ak. VIII, 305).

22 "[E]1 pueblo no cifra su máxima dicha en la libertad, sino en sus fines naturales, los cuales se concretan en estos tres aspectos: esperar bienaventuranza tras la muerte, contar con que una ley pública garantice lo suyo en esta vida entre sus semejantes y, por último, el goce físico de la vida en sí misma (esto es, la salud y la longevidad. La Facultad de Filosofia, sin embargo, sólo puede admitir todos esos deseos a través de prescripciones tomadas de la razón y, permaneciendo adicta al principio de la libertad, se limita a sostener aquello que el hombre debe y puede hacer: vivir honestamente, no cometer injusticias, mostrarse moderado en el goce y paciente en la enfermedad [...]; para todo esto no se requiere, claro está, una gran sabiduría, pues en gran parte todo se reduce al hecho de que uno refrene sus inclinaciones y confie la batuta a su razón, algo que, sin embargo, no le interesa en absoluto al pueblo por representar un esfuerzo personal [...]. Da la impresión de que el pueblo se dirigiera al erudito como a un adivino o un hechicero familiarizado con las cosas sobrenaturales; pues el ignorante gusta de forjarse una idea exagerada acerca de las cualidades de sabio a quien exige algo excesivo. Por eso resulta fácil presumir que, si alguien es lo bastante osado como para hacerse pasar por taumaturgo, éste conquistará al pueblo y le hará abandonar con desprecio el bando de la Facultad de Filosofía. [...] El pueblo quiere ser 
Libertad y orden en la Filosofía política kantiana. Acerca de los límites del uso público de la razón...

guiado, esto es (en palabras de los demagogos), ser embaucado [...], éste propende naturalmente hacia aquello que le obligue a esforzarse lo menos posible..." (SF, Ak. VII, 29-31). Deberíamos considerar, por otra parte, si ha de responsabilizarse sólo al individuos por esta tendencia a rehuir todo esfuerzo personal, o bien existen ciertas condiciones sociales que fomentan la pereza que impide a los hombres hacer uso de su propio entendimiento. En el escrito sobre la Ilustración, Kant parece responsabilizar al individuo por permanecer en ese estado de minoría de edad al señalar que "[u]no mismo es el culpable de dicha minoría de edad cuando su causa no reside en la falta de entendimiento, sino en la falta de resolución y valor para servirse del suyo propio sin la guía del de algún otro", atribuyendo la prolongación indefinida de esta minoría de edad a la "pereza y cobardía" [Faulheit und Feigheit] (cf. WA, Ak. VIII, 35). Sin embargo, más adelante se refiere ciertas las condiciones sociales y culturales que incidirían asimismo la prolongación de ese estado: "El que la mayor parte de los hombres (incluyendo a todo el bello sexo) consideren el paso hacia la mayoría de edad como algo harto peligroso, además de muy molesto, es algo por lo cual velan aquellos tutores que tan amablemente han echado sobre sí esa labor de superintendencia. Tras entontecer primero a su rebaño e impedir cuidadosamente que esas mansas criaturas se atrevan a dar un solo paso fuera de las andaderas donde han sido confinados, les muestran luego el peligro que les acecha cuando intentan caminar solos por su cuenta y riesgo. [...]. Así pues, resulta difícil para cualquier individuo el zafarse de una minoría de edad que casi se ha convertido en algo connatural. Incluso se ha encariñado con ella y eso le hace sentirse realmente incapaz de utilizar su propio entendimiento, dado que nunca se le ha dejado hacer ese intento. Reglamentos y fórmulas, instrumentos mecánicos de un uso racional -o más bien abuso- de sus dotes naturales, constituyen los grilletes de una permanente minoría de edad" (WA, Ak. VIII, 36). Podría afirmarse, pues, que la minoría de edad (diametralmente opuesta a la Ilustración) no sólo es resultado de una incapacidad o falta de disposición individual, sino que ha de ser explicada, en parte, en relación con ciertas condiciones sociales y culturales (vid. 2005, Deligiorgi, 57-59).

${ }^{23}$ Vid. Williams, 2001, 693-722. Señala Aramayo al respecto que "Kant apuesta decididamente por la vía de una paulatina reforma institucional que $[. .$.$] haga superfluo el$ recurrir a un traumático proceso revolucionario" (Aramayo, 2001a, 299). En tal sentido sugiere el autor que el uso público de la razón puede ser considerado acaso como el antídoto más apropiado contra las revoluciones (cf. Aramayo, 2001a, 298-301).

${ }^{24} \mathrm{Cf}$. Clarke, 1997, 53-73.

${ }^{25}$ Esta limitación parece hallarse en tensión con el carácter intrínsecamente comunicativo y participativo que Kant asigna a la razón en diversos textos (cf. $\log$., Ak. IX, 56; KU, Ak. V, 293-294; Refl. 2565, 2564, 2566, Ak. XVI, 418-420; WDO, Ak. VIII, 144), en los que sugiere que la participación de un individuo en procesos de argumentación pública resulta fundamental para el pleno ejercicio de su derecho a desarrollar su propio pensamiento, así como para el ejercicio de su derecho natural (e innato) a comunicar sus ideas y pensamientos ante otros (cf. MS, Ak. VI, 237-238). Para un análisis de la concepción kantiana de la razón como facultad naturalmente comunicativa, vid. Deligiorgi, 2002; Deligiorgi, 2005, 55ss.; La Rocca, 2006, 118ss.

${ }^{26} \mathrm{Cf}$. Deligiorgi 2005, 65ss.

27 "Sea cual fuere su contenido, las doctrinas cuya exposición se halla el gobierno facultado para imponer a las Facultades superiores mediante sanción no pueden ser tomadas ni respetadas sino como un mero estatuto que nace de su voluntad y que, como todo saber humano, no es infalible. Mas como su verdad no puede serles indiferentes, tienen que someterse bajo ese respecto a la razón (por cuyos intereses ha de velar la Facultad de Filosofia), algo que no es posible salvo fomentando una plena libertad para el examen público de dichas doctrinas y, como los preceptos arbitrarios, por muy alta que sea su instancia sancionadora, no siempre vienen a coincidir con las leyes consideradas necesarias por la razón, tal discrepancia originará un conflicto de las Facultades superiores para con la inferior" (SF, Ak. VII, 32).

${ }^{28}$ Cf. SF, Ak. VII, 18.

${ }^{29} \mathrm{Cf}$. SF, Ak. VI, 34.

${ }^{30}$ En el escrito sobre la Ilustración, Kant utiliza la noción de público en un sentido más restringido, al indicar que "en cuanto esta parte de la maquinaria sea considerada como miembro de una comunidad global e incluso cosmopolita y, por lo tanto, se considere su condición de alguien instruido que se dirige sensatamente a un público mediante sus escritos, entonces resulta obvio que puede razonar sin afectar con ello a esos asuntos en donde se vea parcialmente concernido como miembro pasivo" (WA, Ak. VIII, 37). Como ha sido señalado, la noción de público cobra diversos sentidos (más o menos inclusivos) en los escritos políticos kantianos, refiriéndose, según el caso, a los doctos o letrados, a los académicos universitarios, a la comunidad filosófica, o bien al pueblo en su totalidad (cf. Clarke, 1997, 53-73; Davis, 1992, 170- 184). Cf. infra

${ }^{31}$ En la segunda parte de El conflicto de las Facultades (Replanteamiento de la cuestión sobre si el género humano se halla en continuo progreso hacia lo mejor [Erneuerte Frage: Ob das menschliche Geschlecht im beständigen Fortschreiten zum Besseren sei]), señala Kant que la voz de los filósofos o ilustrados [Aufklärer] "no se dirige confidencialmente al pueblo (que bien escasa o ninguna constancia tiene de sus escritos), sino que se dirige respetuosamente al Estado, suplicándole que tome en cuenta la exigencia jurídica de aquél; lo cual no puede tener lugar sino por el camino de la publicidad..." (Ak. VII, 89).

${ }^{32}$ Para un análisis de la concepción kantiana del republicanismo, vid. Bertomeu, 2005; Velasco Gómez, 2005; Dreier, 2005. Si bien Kant suele ser inscripto en las filas del repu- 
blicanismo moderno (vid. Bielefeldt, 1997, Colomer, 1994), ha sido señalada, asimismo, su filiación con la corriente liberal (vid. Dotti 2005; Dotti, 1985, 33). A estas diversas líneas de interpretación ha de añadirse aún aquella lectura que acentúa los rasgos conservadores del pensamiento político kantiano y, en particular, su proximidad respecto del modelo hobbesiano de justificación del poder político (vid. Astorga, 1998). Por nuestra parte, consideramos que diversas tradiciones del pensamiento político convergen en la doctrina jurídico-política kantiana (Beade, 2007; Beade, 2009). Especialmente llamativo resulta que los autores que recurren a la oposición libertad negativa / libertad positiva, no concuerden respecto de cuál de estos dos modos aparentemente contrapuesto de concebir la libertad cobra primacía en los escritos políticos kantianos (vid. Berlin, 1992, 218ss.; Bobbio, 1995, 97-98). Para un análisis crítico acerca de ciertas dificultades implícitas en la oposición libertad positiva /libertad negativa, vid. Skinner, 2005; Taylor, 1979; Pettit, 2004a, 40-45; Pettit, 2004b.

${ }^{33}$ Mittelstraß, 2005, 39ss.

${ }^{34}$ En tal sentido señala, por ejemplo, que las Facultades superiores "nunca renunciarán a su afán de dominio" (SF, Ak. VII, 33), lo cual denota un claro reconocimiento de la necesidad del gobierno de ejercer influencia sobre el pueblo a través de aquéllas, siendo esta influencia una condición básica y quizás inevitable de la gobernabilidad.

${ }^{35}$ Quizás cabría afirmar que en ciertos pasajes de $E l$ conflicto de las Facultades Kant ofrece una descripción realista del orden político, por contraposición a la concepción normativa del Estado, formulada en los Principios metafisicos del derecho. En efecto, en el escrito de 1798 no se describe ya el Estado en la idea, sino que parece indicarse, antes bien, lo que de hecho podemos esperar del gobierno -y, en general, de todo aquel que participa de la conducción del Estado-, a saber: que defienda sus intereses propios y procure mantenerse en el poder, afianzando su dominio a través de diversos mecanismos institucionales (entre los cuales se incluyen las diversas instituciones educativas, y entre ellas, la Universidad). En todo caso, quizás estas aproximaciones diversas a la realidad política no resulten necesariamente incompatibles: en efecto, ambas iluminan bajo una luz diversa los múltiples aspectos bajo los cuales la reflexión filosófica puede abordar la complejidad del orden político-jurídico.

${ }^{36}$ Cf. TP, Ak. VIII, 299

${ }^{37}$ Williams se refiere a dicha tensión, al señalar: "[A]t times he [Kant] appears to be advocating the most radical of political changes (when donning his philosophical hat), and, at others, he appears to be advocating the most cautious of conservatism (when donning his every day, realist hat). [...] Is [..] the conservative attitude which predominates in Kant's vision of politics. Because it is as ideals to to be achieved in the long run that Kant adheres to republican principles; whereas obedience to the power that be, and a pragmatic acceptance of the existing social structure, are the most immediate and pressing duties for the citizen to observe" (Williams,
1983, 179). Kersting parece referirse a esta misma tensión subyacente en el pensamiento político kantiano: "Despite all radicalism of legal Reason, under historical conditions of conflict, Kant gives preference to order over justice and preference to the authority of the state over the authority of human and civil rights". Kersting (1999, 63). Si bien coincidimos con ambos autores respecto de la necesidad de reconocer esta tensión, y su incidencia en el tratamiento kantiano de diversos problemas político-jurídicos, consideramos, no obstante, que una recta evaluación acerca de los rasgos conservadores del pensamiento político de Kant requeriría de un análisis pormenorizado de diversos aspectos doctrinales, tales como su concepción de la soberanía (vid. Beade, 2013); Bielefeldt, 1997; Kaufman, 1997), su posición respecto del derecho de ciudadanía (vid. Abellán, 1996; Beade, 2012; Villacañas 1987, 221-227) y, finalmente, su impugnación del derecho de resistencia (vid. Atkinson 1992, 242ss.; Hancok 1975, Nicholson 1976, Nichoolson, 1992; Ripstein, 2009, 327ss.; Witt, 1999; Kersting, 2007, 354-396; Guyer, 2006, 284-290; Witt 1999; Aramayo, 1993, pp. X-XXVII; Beiser, 1992, 53-56; Pinkard (1999); Mulholland, 1990, 338s.; Beade, 2014).

${ }^{38}$ Esta limitación es establecida claramente incluso en aquellos pasajes en los que Kant reivindica la libertad de expresión. En Teoría y Práctica, se refiere al derecho inalienable del ciudadano de "dar a conocer públicamente su opinión acerca de lo que en las disposiciones de ese soberano le parece haber de injusto para con la comunidad" e incluso caracteriza a la libertad de pluma como "el único paladín de los derechos del pueblo" (TP, Ak. VIII, 304), señalando, sin embargo, que esta libertad debe ser ejercitada "dentro de los limites del respeto y el amor a la constitución en que se vive, gracias al modo de pensar liberal de los súbditos, también inculcado por esa constitución, para lo cual las plumas se limitan además mutuamente por sí mismas con objeto de no perder su libertad" (TP, Ak. VIII, 304). En Qué significa orientarse en el pensamiento? [Was heisst: Sich im Denken orientieren?, 1786] reivindica la libertad de pensamiento como "el único tesoro que todavía nos queda en medio de todas las cargas civiles" (WDO, Ak. VIII, 144) y, no obstante, observa a continuación que la razón ha de someterse a la ley que ella se dicta a sí misma, pues en caso contrario quedará irremediablemente sujeta a leyes externas: "Así, la inevitable consecuencia de la ausencia explícita de ley en el pensamiento (de una liberación de las limitaciones puestas por la razón) es ésta: que la libertad de pensar finalmente se pierde por ligereza, en el sentido propio de la palabra. [...] Aquí interviene entonces la autoridad para impedir que los asuntos civiles caigan en el mayor desorden; y, como para ella el mejor medio es el más rápido y el más enérgico, suprime la libertad de pensar y somete esta cuestión, como todas las otras, a los reglamentos del país. Y así se destruye a sí misma la libertad de pensar,cuando quiere proceder independientemente de las leyes de la razón" (WDO, Ak. VIII, 145-146).

${ }^{39} \mathrm{Cf}$. SF, Ak. VII, 34 . 